\title{
Are the Neural Correlates of Consciousness in the Front or in the Back of the Cerebral Cortex? Clinical and Neuroimaging Evidence
}

\author{
-Melanie Boly, ${ }^{1,2}$ Marcello Massimini, ${ }^{3,4}$-Naotsugu Tsuchiya, ${ }^{5,6}$ Bradley R. Postle, ${ }^{2,7}$ Christof Koch, ${ }^{8}$ \\ and Giulio Tononi ${ }^{2}$ \\ ${ }^{1}$ Department of Neurology, University of Wisconsin, Madison, Wisconsin 53705, ${ }^{2}$ Department of Psychiatry, University of Wisconsin, Madison, Wisconsin \\ 53719, ${ }^{3}$ Department of Biomedical and Clinical Sciences Luigi Sacco, University of Milan, Milan 20157, Italy, ${ }^{4}$ Instituto Di Ricovero e Cura a Carattere \\ Scientifico, Fondazione Don Carlo Gnocchi, Milan 20148, Italy, ${ }^{5}$ School of Psychological Sciences, Faculty of Medicine, Nursing, and Health Sciences, \\ Monash University, Melbourne, 3800 Victoria, Australia, ${ }^{6}$ Monash Institute of Cognitive and Clinical Neuroscience, Monash University, Melbourne, 3800 \\ Victoria, Australia, ${ }^{7}$ Department of Psychology, University of Wisconsin, Madison, Wisconsin 53705, and ${ }^{8}$ Allen Institute for Brain Science, Seattle, \\ Washington 98109
}

The role of the frontal cortex in consciousness remains a matter of debate. In this Perspective, we will critically review the clinical and neuroimaging evidence for the involvement of the front versus the back of the cortex in specifying conscious contents and discuss promising research avenues.

Key words: consciousness; frontal cortex; lesion studies; neuroimaging; stimulation studies

\section{Introduction}

Consciousness is subjective experience, the "what it is like" to perceive a scene, recognize a face, hear a sound, or reflect on the experience itself (Tononi et al., 2016a). Identifying the neural correlates of consciousness is important scientifically and clinically, to improve the detection of awareness and to design new therapies in patients who remain unresponsive after brain damage (Gosseries et al., 2014). Although frontal cortex is crucial for intelligent behavior and cognitive control, its involvement in consciousness remains a matter of debate (Koch et al., 2016a). It has been widely assumed that prefrontal circuits are essential for consciousness, either alone (Del Cul et al., 2009) or in conjunction with parietal areas (frontoparietal network) (Bor and Seth, 2012; Laureys and Schiff, 2012). In this Perspective, we will critically review the evidence for the role of the "front" versus the "back" of the cortex in supporting consciousness. By the "front," we refer to prerolandic neocortex, including dorsolateral, medial

\footnotetext{
Received March 12, 2017; revised June 28, 2017; accepted June 30, 2017.

This work was supported by National Institutes of Health Grant 1R03NS096379 to M.B., the James S. McDonnell Scholar Award 2013 and the H2020-FETOPEN-2014-2015-RIA under agreement No. 686764 (Luminous Project) to M.M., the Templeton World Charity Foundation to N.T., National Institutes of Health Grant MH095984 to B.R.P., and the Tiny Blue Dot Foundation and the Distinguished Chair in Consciousness Science (University of Wisconsin) to G.T. The authors declare no competing financial interests.

Correspondence should be addressed to either Dr. Melanie Boly or Dr. Giulio Tononi, 6001 Research Park Boulevard, Madison WI 53719. E-mail: boly@wisc.edu or gtononi@wisc.edu.

DOI:10.1523/JNEUROSCI.3218-16.2017

Copyright $\odot 2017$ the authors $\quad 0270-6474 / 17 / 379603-11 \$ 15.00 / 0$
}

prefrontal, anterior cingulate, and orbitofrontal areas. By the "back," we refer to neocortical regions within the parietal, occipital, and lateral temporal lobes. Due to space constraints, we will not review possible contributions to consciousness of the medial temporal lobe and of the insular cortex (Craig, 2010; Seth et al., 2011; Quiroga, 2012), except for pointing out that consciousness is preserved after bilateral lesions of these areas (Corkin, 2002; Damasio et al., 2013). We will also not discuss the essential role of different brainstem and subcortical mesocircuit structures in regulating the level of consciousness (Brown et al., 2010). We emphasize, however, that consciousness is absent in vegetative state (VS) patients who suffered widespread corticothalamic damage even when brainstem activity is preserved (Laureys et al., 2004). We refer to other reviews for the complex interplay between consciousness, memory, and attention (Tononi et al., 2016b; Tsuchiya and Koch, 2016), including spatial neglect (Corbetta and Shulman, 2011). Finally, we will focus on the empirical evidence about the role of the front and the back of cortex leaving aside theoretical interpretations and predictions (Lamme, 2006; Dehaene and Changeux, 2011; Lau and Rosenthal, 2011; Boly and Seth, 2012; Tononi et al., 2016a).

Distinguishing between the neural correlates of consciousness and other neural processes

Neural correlates of consciousness: definition

The neural correlates of consciousness (NCC) are defined as the minimal neural mechanisms jointly sufficient for any one con- 


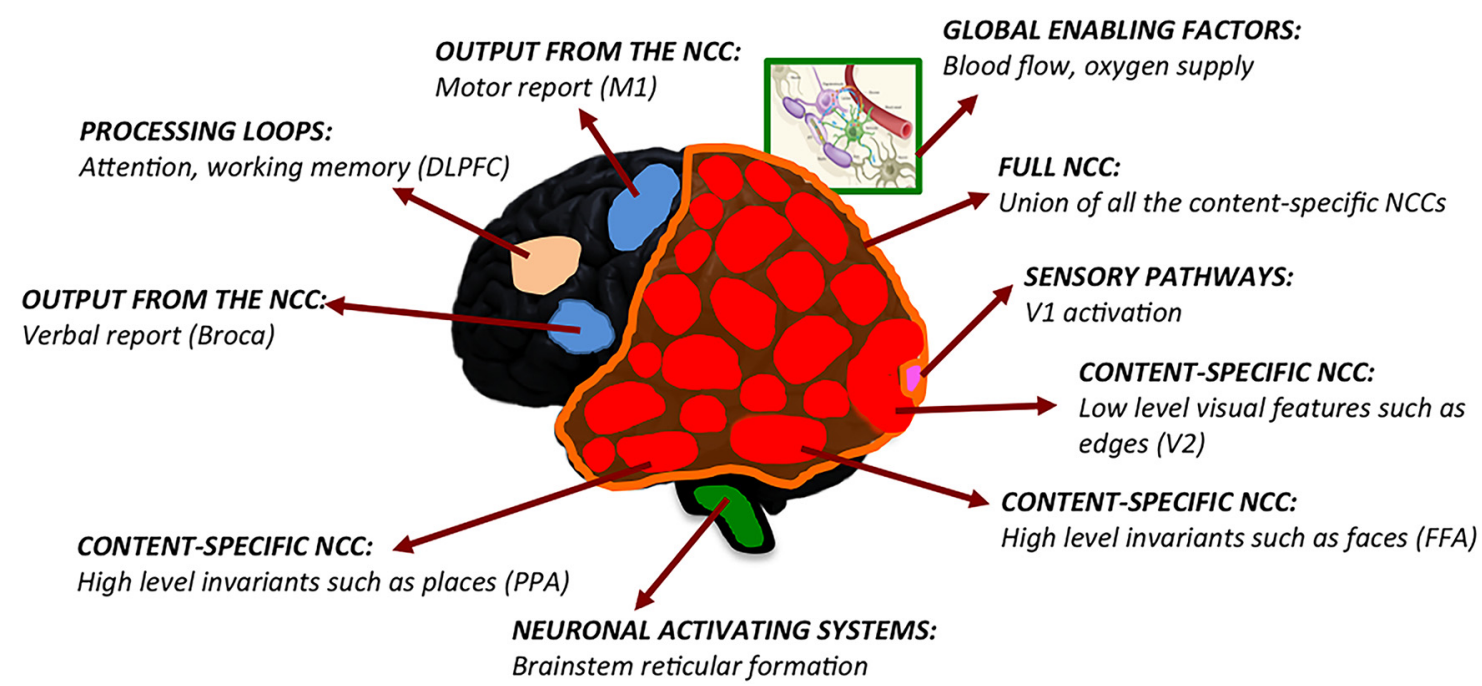

Figure 1. Definition of the NCC. Content-specific NCC (red) directly contribute to phenomenal distinctions (e.g., low-level visual features, faces, or places) within consciousness. The full NCC (orange) is constituted by the union of all the content-specific NCC. Background conditions to the NCC encompass neural processes that enable or modulate the activity of the full NCC and thus influence the level of consciousness (green), including global enabling factors, such as blood flow or oxygen supply, and neuronal activating systems, such as brainstem reticular formation; neural processes that modulate the activity of only some content-specific NCC, including processing loops involving attention or working memory (beige), sensory pathways activating primary sensory cortices (pink), and outputs from the NCC (blue) involved in task-related verbal or motor reports. V1, Primary visual cortex; V2, secondary visual cortex; PPA, parahippocampal place area; M1, primary motor cortex.

scious percept (Crick and Koch, 1990). Content-specific NCC are the neural mechanisms specifying particular phenomenal contents within consciousness, such as colors, faces, places, or thoughts. Experimentally, content-specific NCC are typically investigated by comparing conditions where specific conscious contents are present versus absent. The full NCC can be defined as the union of all content-specific NCC (Koch et al., 2016a). Experimentally, the full NCC can be identified by comparing conditions where consciousness as a whole is present versus absent, such as dreaming versus dreamless sleep. In principle, the full NCC can also be approximated by sampling the wide range of content-specific NCC. In practice, these two approaches progress hand in hand (Boly et al., 2013).

\section{Distilling the "true NCC"}

Recent results have stressed the importance of dissociating the true NCC from other neural processes (Miller, 2007; de Graaf et al., 2012; Tsuchiya et al., 2015) that can be considered as "prerequisites" and "consequences" of consciousness (Aru et al., 2012) or alternatively as preceding and following the experience itself (Pitts et al., 2014). Here, factors that modulate the NCC without being directly involved in specifying conscious contents will be called "background conditions" (Koch et al., 2016a) of several kinds (Fig. 1). For example, global enabling factors, such as blood flow or oxygen supply to the cortex, are obviously essential for consciousness, but they do not contribute directly to its contents. Similarly, neuronal activating systems, such as cholinergic and noradrenergic neuromodulation, diffuse thalamocortical projections, and the anterior forebrain mesocircuit, are likely to influence the level of consciousness only indirectly, by modulating the activity of large parts of the full NCC (Schiff, 2010; de Graaf and Sack, 2014). Processing loops involving selective attention, working memory, or expectation may also modulate the probability of specific conscious contents indirectly, by modifying the excitability of content-specific NCC in a task-dependent manner (Aru et al., 2012) concurrently with experience (Postle, 2015; Tononi et al., 2016a). Finally, specific contents of experience are specified by the cortical NCC whether they are induced by sensory stimuli, imagined, or dreamt, suggesting that neural activity along sensory pathways serves as a reliable but indirect trigger of experiential content, rather than contributing directly to it. Similarly, neural activity along motor pathways is essential for reporting the contents of consciousness, but not for experiencing them (Tsuchiya et al., 2015).

Several complementary methods can be used to distill the true NCC. For the full NCC, within-state paradigms can be used to avoid confounds due to changes in behavioral state and task performance as well as to dissociate unconsciousness from unresponsiveness. For example, within either non-rapid eye movement (NREM) or REM sleep one can contrast neural activity when subjects report having dreamt ( $\sim 60 \%$ of cases in NREM sleep, $\sim 95 \%$ of cases in REM sleep) versus having been unconscious. Patients can also be conscious, although unresponsive and disconnected from the environment, in $\sim 20 \%$ of cases during anesthesia (Sanders et al., 2012) and in $\sim 35 \%$ of cases during complex partial seizures (Johanson et al., 2003). In such cases, methods assessing the complexity of neural EEG responses to transcranial magnetic stimulation can be used to assess the presence versus absence of consciousness in unresponsive subjects (Casarotto et al., 2016). For content-specific NCC, experiments can be carefully designed to systematically investigate possible dissociations between the experience of particular conscious contents and the engagement of various cognitive processes, such as attention, decision-making, and reporting (Aru et al., 2012; Koch and Tsuchiya, 2012; Tsuchiya et al., 2015; Tsuchiya and Koch, 2016). It is especially important to assess the association between the activity of a candidate NCC and the presence of a particular conscious content systematically, across a large number of different experiments (Crick and Koch, 1990). Machine learning approaches can also be used to identify the true NCC as the neural activity patterns most predictive for specific conscious percepts (Sandberg et al., 2014). Ideally, dissociation, association, and prediction approaches applied to lesion, stimulation, and recording studies will converge in identifying a reliable and specific contentspecific NCC (Koch et al., 2016a). In that case, one should assume 


\section{FULL NCC}

A

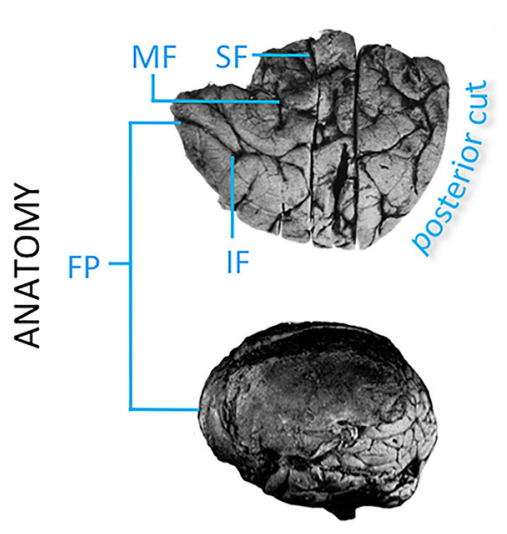

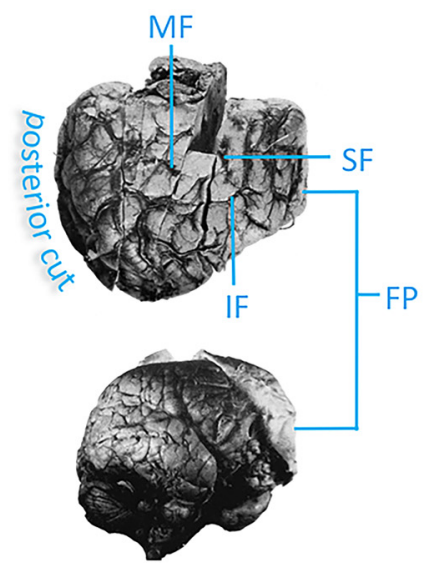

B

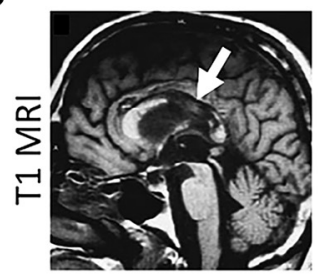

C

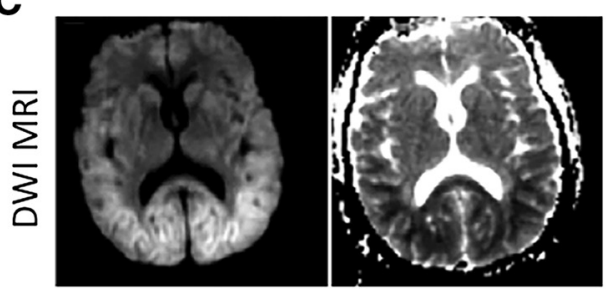

\section{CONTENT-SPECIFIC NCC}

D

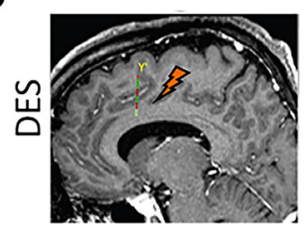

$\mathrm{E}$

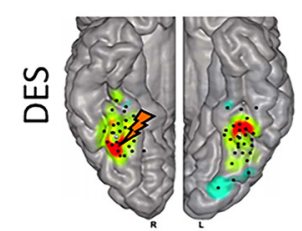

$F$

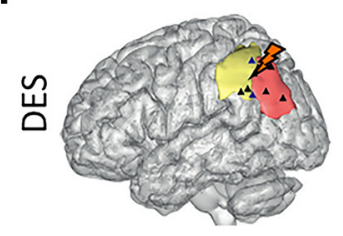

Figure 2. Clinical evidence. Full NCC. $\boldsymbol{A}$, Complete bilateral prefrontal lobectomy does not noticeably change the level of consciousness. Top row, Bilateral views of the resected left and right frontal lobes (Brickner, 1936). Bottom row, Postmortem lateral views of both hemispheres (Brickner, 1952). $\boldsymbol{B}$, Anoxic lesions of posterior corpus callosum predict permanent VS after head trauma (Kampfl et al., 1998). C, Lesions of posterior corpus callosum, with restricted diffusion extending to parieto-temporooccipital regions, predict permanent coma after anoxic brain damage (Bianchi and Sims, 2008). Content-specific NCC. D, A recent study suggests that intrusive thoughts can be elicited by electrical stimulation of anterior cingulate cortex (Popa et al., 2016). Eliciting any experience is, however, far more common when stimulating posterior than anterior cortical structures (Selimbeyoglu and Parvizi, 2010). $\boldsymbol{E}, \boldsymbol{F}$, Direct electrical brain stimulation (DES) supports a causal role for different parts of the posterior cortex in specifying conscious content, for example, the right FFA in contributing to face percepts (Rangarajan et al., 2014) $(\boldsymbol{E})$ and the parietal cortex contributing the feeling of intention to move $(\boldsymbol{F})$ (Desmurget et al., 2013). SF, Superior frontal sulcus; MF, middle frontal sulcus; IF, inferior frontal sulcus; DWI, diffusion weighted imaging.

operationally that the relevant part of the brain contributes directly to consciousness: that is, it constitutes a part of its physical substrate (Tononi et al., 2016a). With these methodological clarifications at hand, we will now critically review evidence for the NCC in the front versus the back of the cerebral cortex.

\section{Clinical evidence for a contribution of anterior versus posterior cortex to consciousness \\ Lesions}

Lesion data offer strong causal evidence for the involvement or lack of involvement of different brain areas in supporting consciousness and its contents (Farah, 2004). With regards to the full NCC, several well-documented patients have been described with a normal level of consciousness after extensive frontal damage. For example, Patient A (Brickner, 1952) (Fig. 2A), after extensive surgical removal of the frontal lobes bilaterally, including
Brodmann areas $8-12,16,24,32,33$, and 45-47, sparing only area 6 and Broca's area (Brickner, 1936), "toured the Neurological Institute in a party of five, two of whom were distinguished neurologists, and none of them noticed anything unusual until their attention was especially called to A after the passage of more than an hour." Patient KM (Hebb and Penfield, 1940) had a near-complete bilateral prefrontal resection for epilepsy surgery (including bilateral Brodmann areas 9-12, 32, and 45-47), after which his IQ improved. Patients undergoing bilateral resection of prefrontal cortical areas for psychosurgery (Mettler et al., 1949), including Brodmann areas $10,11,45,46,47$, or 8,9 , 10 , or $44,45,46,10$, or area 24 (ventral anterior cingulate), remained fully conscious (see also Penfield and Jasper, 1954; Kozuch, 2014; Tononi et al., 2016b). A young man who had fallen on an iron spike that completely penetrated both frontal lobes, affecting bilateral Brodmann areas $10,11,24,25,32$, and 45-47, and areas 44 and 6 on the right side, went on to marry, raise two children, have a professional life, and never complained of perceptual or other deficits (Mataró et al., 2001). A young woman with massive bilateral prefrontal damage of unclear etiology, affecting the right basal, superior, medial and lateral PFC, and the left medial orbitofrontal, frontopolar, and frontal gyri (Markowitsch and Kessler, 2000), had deficits in cognitive functions supported by the frontal lobe, but her consciousness and perceptual abilities were preserved. Medial prefrontal lesions, especially those involving anterior cingulate cortex, can cause akinetic mutism (Cairns et al., 1941), where patients visually track examiners but do not respond to command. Patients who recover from this state typically report that they were conscious but lacked the motivation to respond (Damasio and Van Hoesen, 1983).

Moving to the back of the brain, broad bilateral lesions or ablations of posterior cortex are extremely rare (Cavanna and Trimble, 2006). However, traumatic lesions of the posterior corpus callosum, connecting large parts of the posterior cortex, are found in $98 \%$ of patients who remain in VS after 1 year (Kampfl et al., 1998) (Fig. 2B). Moreover, such lesions are associated with a 214-fold risk of permanent VS (Kampfl et al., 1998). Posterior corpus callosum lesions also predict permanent coma after cardiac arrest (Bianchi and Sims, 2008) (Fig. 2C). By contrast, traumatic lesions of the frontal lobe, which are found in approximately half of patients with traumatic VS in the acute phase, do not predict outcome (Kampfl et al., 1998).

With regards to content-specific NCC, there is abundant neurological evidence that lesions in the posterior cortex can cause a loss of specific contents of experience (Farah, 2004). For example, lesions of the right fusiform face area (FFA) cause prosopagnosia, 
an inability to recognize faces (Barton and Cherkasova, 2003). Lesions of inferolateral occipital cortex cause achromatopsia, an inability to distinguish colors (Barton, 2011) that, when severe, can be accompanied by unawareness of the deficit (von Arx et al., 2010). Other lesions of the occipital cortex lead to visual form agnosia, a selective inability to identify objects, or simultanagnosia, an inability to perceive more than one object at a time (Farah, 2004). Lesions of the postrolandic cortex lead to a loss of somatosensory percepts, and lesions of left and right angular gyrus impair the conscious understanding of speech and prosody, respectively (George et al., 1996), whereas lesions of the inferior parietal lobule cause a loss of motor awareness (Sirigu et al., 2004). Lesions in left lateral temporal cortex may also lead to selective deficits for the perception of single words or full sentences (Blumenfeld, 2011).

By contrast, there is little evidence for loss of specific conscious contents after frontal damage (Penfield and Jasper, 1954). For example, lesions of Broca's area, while impairing speech production, do not typically cause loss of conscious speech perception (Blumenfeld, 2011). Although frontal injuries can slightly increase the threshold for perceiving some brief $(16 \mathrm{~ms})$ and masked visual stimuli, patients still experience them (Del Cul et al., 2009), suggesting that these frontal regions may modulate the NCC (i.e., act as background conditions) rather than contributing directly to consciousness (Kozuch, 2014).

\section{Stimulation studies}

Electrical stimulation during neurosurgery is an important source of evidence for a direct contribution of different brain areas to consciousness (Penfield, 1959; Desmurget et al., 2013), as indicated by its superior value in predicting postoperative deficits compared with fMRI or diffusion tensor imaging (Borchers et al., 2011).

With regards to the full NCC, the classical study of Moruzzi and Magoun (1949) and subsequent studies showed that it is possible to restore EEG activation and behavior in anesthetized animals through electrical or pharmacological stimulation of neuronal activating systems in brainstem, thalamus, and basal forebrain. Recently, subcortical electrical stimulation has also succeeded in increasing the level of consciousness in animals with focal seizures (Kundishora et al., 2017) and in human patients after brain damage (Schiff et al., 2007). In these cases, it is likely that the effects were mediated indirectly, by modulating the excitability of the full NCC through arousal systems.

With regards to content-specific NCC, it was recognized long ago that electrical stimulation of most of the frontal cortex does not elicit content-specific changes in experience (Penfield and Jasper, 1954), although it can interfere with task execution and induce involuntary movements (Selimbeyoglu and Parvizi, 2010). Transcranial magnetic stimulation of the frontal cortex also does not seem to modify experiential content, although it can interfere with speech production (Pascual-Leone et al., 1991). Complex hallucinations, similar to those classically reported after stimulation of temporal and parahippocampal regions (Penfield and Jasper, 1954; Mégevand et al., 2014), have been occasionally reported after stimulation of the middle and inferior frontal gyrus (Blanke et al., 2000), perhaps due to a network effect. Recently, however, two case report studies described the occurrence of a will to persevere and of intrusive thoughts after stimulation of the anterior cingulate cortex (Parvizi et al., 2013) and of midcingulate cortex (Popa et al., 2016) (Fig. 2D), respectively.

Electrical stimulation of posterior cortex induces discrete changes in the contents of consciousness more reliably (Selimbe- yoglu and Parvizi, 2010), although some posteromedial cortical areas may remain silent (Foster and Parvizi, 2017). For example, direct electrical stimulation of early visual areas induces simple visual experiences, such as phosphenes (Beauchamp et al., 2012; Winawer and Parvizi, 2016), which can also be induced by transcranial magnetic stimulation of occipital and parietal cortices (Samaha et al., 2017). Electrical stimulation of postcentral gyrus induces somatosensory percepts (Penfield and Jasper, 1954), stimulation of temporoparietal cortex induces experiences of visual motion (Rauschecker et al., 2011), while stimulation of right fusiform gyrus selectively disrupts the perception of faces (Rangarajan et al., 2014) (Fig. 2E). Moreover, the feeling of intention has been elicited in temporoparietal cortex (Desmurget et al., 2009) (Fig. 2F) and out-of-body experiences in the right angular gyrus (Blanke et al., 2002).

Together, stimulation studies support the idea that some posterior cortical regions may contribute directly to specific contents of experience, but the evidence for prefrontal regions is scarce and indirect.

\section{Neuroimaging evidence for a contribution of the anterior versus posterior cortex to consciousness}

Compared with lesions or electrical stimulations, neuroimaging studies offer less direct evidence for the contribution of any one brain region to consciousness (Farah, 2004). Indeed, functional activation maps frequently encompass brain areas that may not be directly involved in specifying experiential contents (Silvanto and Pascual-Leone, 2012; de Graaf and Sack, 2014). For example, whereas $\mathrm{fMRI}$ and intracranial EEG both reveal the activation of widespread bilateral temporo-occipital areas (beyond the FFA) after the presentation of faces, direct electrical stimulation disrupts face perception only when applied to the right FFA (Rangarajan et al., 2014) (Fig. 2E).

However, neuroimaging experiments can sample brain activity systematically and noninvasively in healthy volunteers (Poldrack and Farah, 2015) and, with appropriate methodologies, they can also provide valuable information about the functional specificity of brain regions (Moran and Zaki, 2013; Poldrack and Farah, 2015). For example, neuroimaging experiments can demonstrate dissociations between content-specific NCC and neural correlates of other cognitive processes (Aru et al., 2012; de Graaf et al., 2012) by relying on forward inference (Henson, 2006; Moran and Zaki, 2013). Moreover, ever-growing neuroimaging databases can demonstrate systematic associations between specific conscious contents and the activation of specific cortical areas by using meta-analytic reverse inference (Poldrack, 2006; Yarkoni et al., 2010; Moran and Zaki, 2013; Poldrack and Yarkoni, 2016). Also, multivariate decoding techniques can compare the predictive value of various NCC candidates for specific conscious percepts (Haynes, 2009; Sandberg et al., 2014).

\section{Forward inference: dissociating the true NCC from correlated neural processes}

As was argued above, the cleanest way to identify the full NCC is to use within-state, no-task paradigms (Fig. $3 A-D$ ), which avoid confounds due to behavioral state changes and dissociate consciousness from behavioral responsiveness and task performance. Withinstate studies contrasting dreaming versus nondreaming during NREM sleep and REM sleep have pointed to a "posterior hot zone" in parieto-occipital areas, possibly extending to midcingulate regions, as a reliable NCC (Siclari et al., 2017). Withinstate contrasts applied to brain-damaged patients, comparing VS to minimally conscious state (MCS), also reveal most consistent 


\section{FULL NCC}

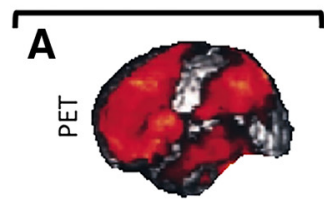

but...
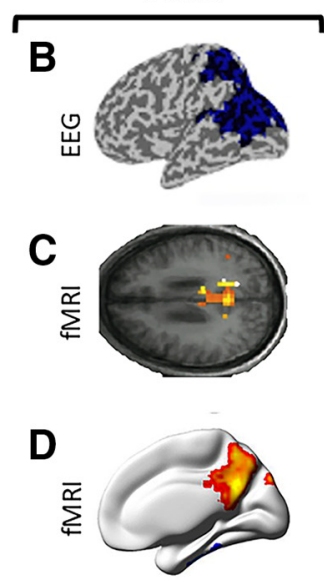

CONTENT-SPECIFIC NCC

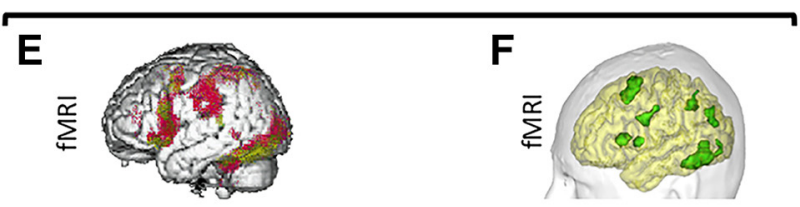

but...

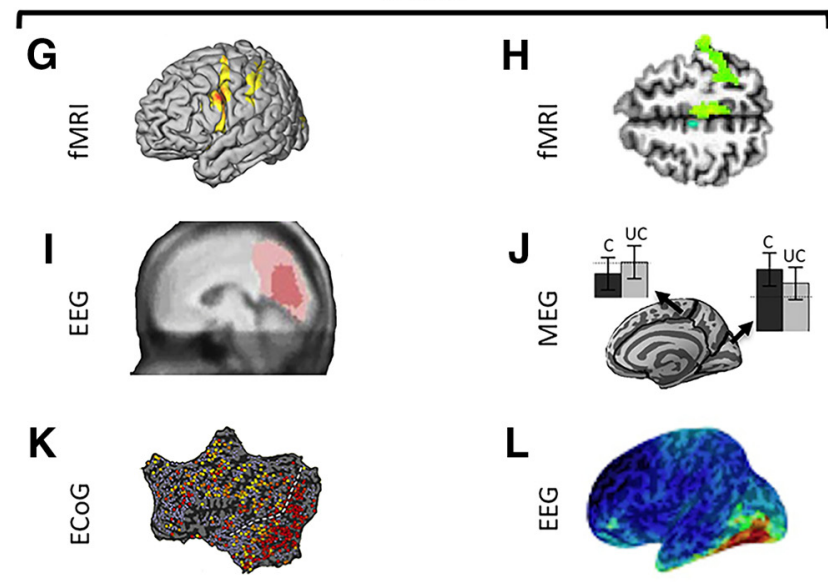

Figure 3. Neuroimaging, Forward inference. Full NCC. $\boldsymbol{A}$, Between-state paradigm contrasting brain activity during NREM sleep and wakefulness (Kajimura et al., 1999) shows a relative deactivation of frontoparietal cortices. $\boldsymbol{B}$, When subjects are awoken from NREM sleep and asked if they experienced anything before being awakened, EEG data during dream experiences show reduced low-frequency activity $(1-10 \mathrm{~Hz}$ ) compared with dreamless sleep in a posterior parieto-occiptal "hot zone" (Siclari et al., 2014). C, D, Directly comparing patients in an MCS with patients in a VS reveals differences in connectivity restricted to posterior cortex. C, Vanhaudenhuyse et al. (2010). D, Wu et al. (2015). Content-specific NCC. $\boldsymbol{E}$, $\boldsymbol{F}$, Tasks involving reporting seen versus unseen stimuli highlight differences in frontoparietal cortices: $\boldsymbol{E}$, Binocular rivalry (Lumer et al., 1998); $\boldsymbol{F}$, Visual word masking tasks (Dehaene et al., 2001). $\mathbf{G}$, When conscious visual perception is dissociated from behavior (i.e., button press), only differences in activity in occipital and parietal regions remain (Frässle et al., 2014). $\boldsymbol{H}$, Conscious perception of weak somatosensory stimuli correlates with cortical changes in B0LD signal restricted to contralateral rolandic and parietal areas (Meador et al., 2017). I, J, An early "visual awareness negativity" 200 ms in posterior temporal and occipital areas is found in two masking paradigms: I, Koivisto and Revonsuo (2010); $\boldsymbol{J}$, Andersen et al. (2016). C, Conscious stimulus; UC, unconscious stimulus. $\boldsymbol{K}$, Visual one-back paradigm in patients implanted with subdural electrode arrays. The visual cortex (right of the dashed white line) responds rapidly to the seen stimulus (red), whereas frontal regions are modulated by the task (yellow) (Noy et al., 2015). L, A within-state no-task experiment (Fig. 1D), contrasting EEG activity during REM sleep dreams with and without faces, highlighted the fusiform gyrus as content-specific NCC (Siclari et al., 2014).

differences within posterior cortex (Vanhaudenhuyse et al., 2010; King et al., 2013; Wu et al., 2015).

With regards to content-specific NCC, many experiments using bistable perception and masking paradigms have shown the activation of prefrontal areas during conscious perception of external stimuli (for a detailed review, see Dehaene and Changeux, 2011). However, these task-based paradigms recruit areas involved in attention, working memory, and other cognitive processes. If these areas are only required for reporting on the perceived stimuli and not for experiencing them, they should not be regarded as a part of the full NCC (Tsuchiya et al., 2015). The recent study of stimuli that are task irrelevant but experienced (Fig. 3E-L) has made it possible to dissociate the true NCC from various cognitive functions involved in behavioral demands (Aru et al., 2012; de Graaf et al., 2012). During both inattentional blindness (Pitts et al., 2012) and backward masking experiments (Pitts et al., 2014), the content-specific NCC for task-irrelevant percepts are located in posterior cortex, whereas a difference in frontal activity (P3 potential) is only present if stimuli are taskrelevant. "No-report" paradigms have also pointed to posterior regions as the NCC, whereas frontal cortex activation is correlated with reporting (Tsuchiya et al., 2015; Koch et al., 2016a). Similar dissociations have been identified by orthogonally manipulating consciousness versus selective attention (Tsuchiya and Koch, 2016), working memory (King et al., 2016), or expectation (Melloni et al., 2011). During REM sleep, a "no-task" state, specific dream contents, such as faces, places, movement, and speech, can be predicted from posterior, but not anterior, cortex (Siclari et al., 2017). The same approach has highlighted a potential contribution of mid-cingulate cortex to conscious thought, whether during waking, NREM, or REM sleep (Perogamvros et al., 2017). Finally, when meditation practitioners become immersed in a state of vivid imagery, activity in their frontal lobe decreases (Lou et al., 1999).

Reverse inference: content-specific NCC versus non-content-specific cognitive processes

In neuroimaging studies, a content-specific NCC can be characterized as the part of the brain in which a change in activity reliably and specifically predicts a particular change in experiential content. In recent years, several open-access frameworks have been developed to pool data from thousands of neuroimaging studies and assess reliability and specificity (Eickhoff et al., 2011; Poldrack and Yarkoni, 2016). For example, the Neurosynth framework (www.neurosynth.org) (Yarkoni et al., 2011) combines an automated tool to extract activation coordinates with a taxonomy of cognitive processes. Despite significant caveats, such as the use of $3 \mathrm{D}$ coordinates of activity peaks rather than unthresholded statistical maps (but see Neurovault, www. neurovault.org) (Gorgolewski et al., 2016) and of functional labels assigned by investigators, these meta-analytic tools can already illustrate reverse inference and generate hypotheses. For example, in a traditional meta-analysis approach, computing the probability that different brain regions are active when the study 


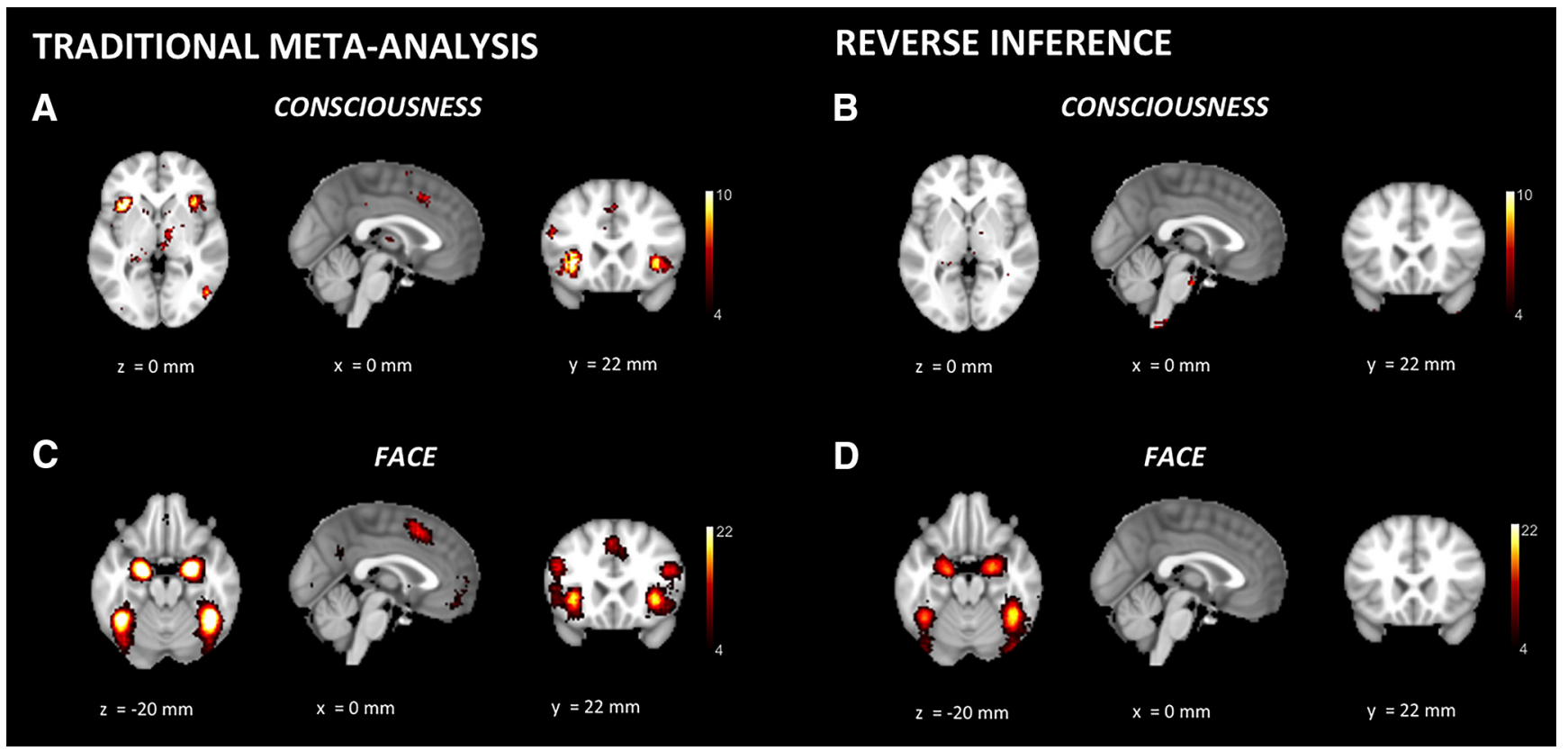

Figure 4. Neuroimaging, Reverse inference. $A$, When using Neurosynth for a traditional meta-analysis, computing the probability that different brain regions are active when the topics of a study include consciousness, parts of frontal cortex show up. $\boldsymbol{B}$. When using Neurosynth in reverse inference mode, computing the probability that consciousness is included within the topics of a study, given the activation of different parts of the brain, frontal cortex disappears. The key term "conscious" was used on the Neurosynth website to extract both "forward" meta-analysis and reverse inference analysis steps in $\boldsymbol{A}, \boldsymbol{B}$. C, The same frontal areas that identified in a traditional meta-analysis for consciousness also appear activated in a traditional meta-analysis for faces. $\boldsymbol{D}$, In contrast, reverse inference for faces no longer identifies frontal cortex activity but rather locates the activation predicting highest probability for face percepts in the right FFA. The key term "faces" was used on the Neurosynth website to extract both "forward" meta-analysis and reverse inference analysis steps in $\boldsymbol{C}, \boldsymbol{D} . \boldsymbol{X}, \boldsymbol{y}, \boldsymbol{Z}$ values represent MNI coordinates, and a color scale is used for $Z$ values.

topics include consciousness, Neurosynth activation maps display some parts of the frontal cortex (Fig. 4A). However, in a reverse inference mode, computing the probability that consciousness is mentioned in the study given the activation of different brain regions, the activation of frontal cortex disappears (Fig. 4B). By contrast, in agreement with lesion and stimulation studies, reverse inference locates the best predictor of face percepts in the right FFA (Fig. 4C,D). Content-specific results for visual words or motion, speech sounds, or touch perception are likewise regionalized to occipital, temporal, and parietal cortices. In all these cases, reverse inference does not highlight frontal areas as predictive for specific conscious contents.

Neurosynth also permits the assessment of the functional specificity of brain areas at user-specified coordinates. For example, activation in the FFA (with coordinate selected from the statistical maximum of the traditional meta-analysis, [41, -49 , $-20]$ ) is consistently predictive for faces (probability $p=0.88$ ), temporo-occipital cortex for visual words $([-46,-54,-12], p=$ 0.86 ) or visual motion $([46,-68,0], p=0.9)$, superior temporal cortex for speech sounds $([-58,-10,0], p=0.84)$, and postcentral cortex for touch $([-54,-22,20], p=0.88)$. In contrast, the statistical maximum within the frontal cortex activation obtained from the traditional meta-analysis on consciousness $(-47,6,28)$ is found to be most predictive for the terms "phonological" and "task" ( $p=0.76$ and $p=0.63$, respectively).

Prospective predictive approaches: decoding consciousness in individual trials/subjects

Ideally, decoding approaches would identify the true NCC as neural activity patterns most predictive for the presence of a given conscious content (Sandberg et al., 2014). Unlike classical statistical analysis, decoding approaches also assess reproducibility as the percentage of accurate classification among single trials (Haynes, 2009). With respect to the full NCC, the best predictors for differentiating MCS from VS using PET or fMRI were located in parietal, temporal, and occipital cortices (Demertzi et al., 2015; Stender et al., 2016) (Fig. 5, top). An online prospective approach based on EEG markers of arousal in posterior cortex was able to predict consciousness (dreaming) versus unconsciousness during NREM sleep with $85 \%$ accuracy (Siclari et al., 2017). Post hoc analysis also located the areas most predictive for dreaming consciousness within temporo-parieto-occipital cortices (Siclari et al., 2017). Anesthesia studies have shown that frontal activity is a poor predictor of consciousness (Avidan et al., 2011; Gaskell et al., 2017), but there are no data so far for posterior cortex.

As for content-specific NCC, numerous studies in both awake and dreaming subjects could decode the occurrence of specific experiential contents from the activity of specific regions of posterior cortex (Nishimoto et al., 2011; Horikawa et al., 2013; Siclari et al., 2017). Working memory contents can also be decoded more reliably from the back than from the front of the cortex (Emrich et al., 2013) (Fig. 5, bottom). Finally, multivariate patterns predictive of differences in subjective experiences both within (Kriegeskorte, 2011) and between subjects (Charest et al., 2014) are most consistently found in posterior cortex.

\section{Conclusion and future directions}

In this Perspective, we have reviewed evidence across lesion, stimulation, and recording studies that consistently point to regions in the "back" of the cortex, including temporal, parietal, and occipital areas, as a "posterior hot zone" that seems to play a direct role in specifying the contents of consciousness. By contrast, evidence for a direct, content-specific involvement of the "front" of the cortex, including most prefrontal regions, is missing or unclear. At a minimum, reports of conscious patients after bilateral frontal lobectomy demonstrate that the prefrontal cortex is not necessary for consciousness. Although most prefrontal 


\section{FULL NCC}
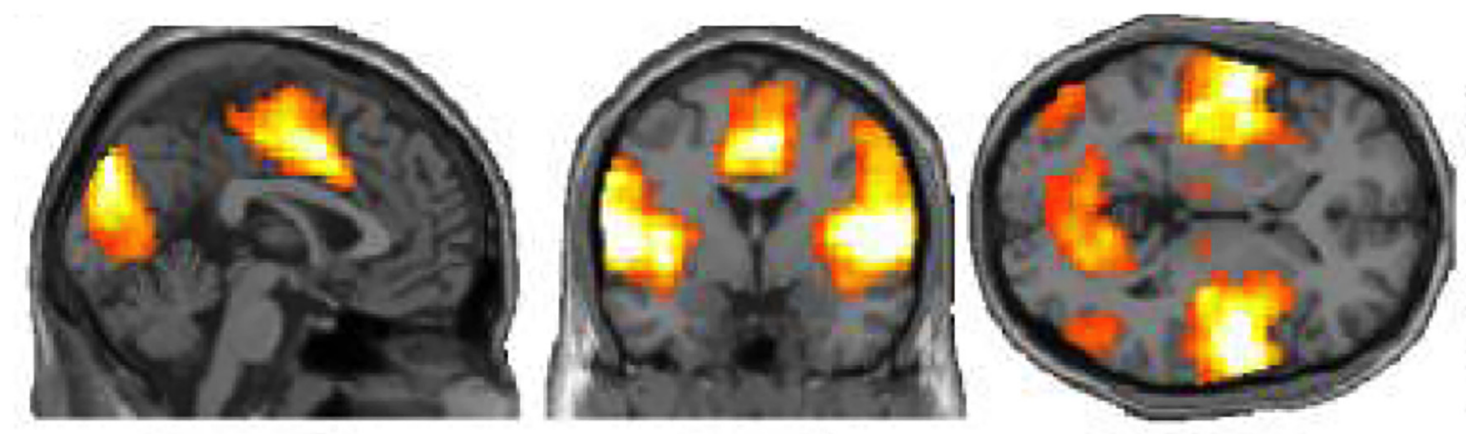

\section{CONTENT-SPECIFIC NCC}
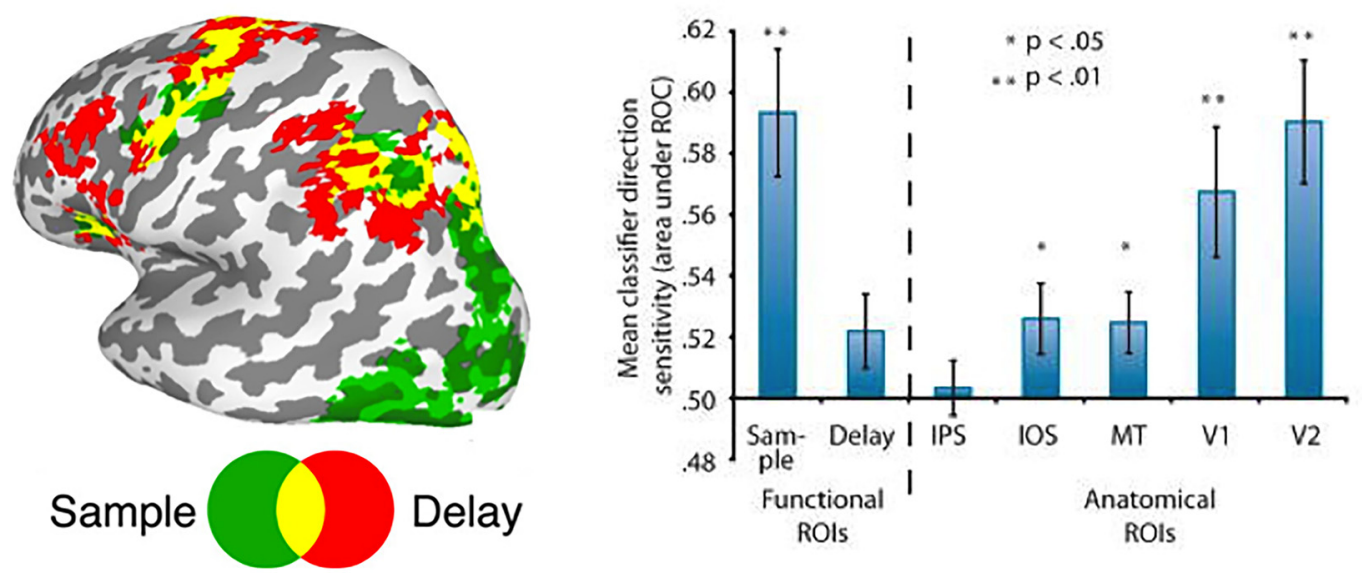

Figure 5. Neuroimaging, Predictive approaches. Full NCC, Machine learning approaches applied to fMRI resting state show that temporo-parieto-occipital connectivity best differentiates patients in MCS versus VS (Demertzi et al., 2015). Content-specific NCC, The contents of a working memory task can best be decoded from the back of the brain (posterior green ROI, activated during sample period), but not from the front of the brain (red fronto-parietal ROl, activated during delay period) (Emrich et al., 2013). Right side panel, Classification accuracy to identify conscious contents is much higher for posterior Sample ROI than for fronto-parietal Delay ROI (left part of panel, before dashed line). Classification accuracy is also higher in occipital areas compared with parietal cortex (right part of panel, after dashed line). IPS, Intraparietal sulcus; IOS, intraoccipital sulcus; MT, area MT; V1, primary visual cortex; V2, secondary visual cortex; ROI, region of interest.

regions may be "mute" as regards to consciousness, not unlike basal ganglia and cerebellum, it remains possible that some prefrontal regions, such as ventromedial areas (Koenigs et al., 2007) or premotor areas, may contribute specific conscious contents, such as feelings of reflection, valuation, and affect (Koch et al., 2016b). Below we discuss some promising future research directions.

\section{Lesion studies}

Lesion studies would benefit from a systematic assessment of loss of specific conscious contents after frontal cortex damage, sampling both task-related experiences as well as dream contents (as in Solms, 2014). Future experiments should also investigate possible dissociations between consciousness and cognitive functions, such as attention and working memory after frontal damage, detail the precise 3D location (as in Mah et al., 2014) and laminar profile (Koch et al., 2016a) of the lesions, and control for network effects (Fischer et al., 2016).

\section{Stimulation studies}

Stimulation studies should explore the effects of local perturbations on both task performance (as in Winawer and Parvizi, 2016) and subjective experience, for example, using structured questionnaires. Direct electrical stimulation combined with intracranial recordings at the stimulation site and at distant sites (as in Keller et al., 2014; Pigorini et al., 2015) should help to identify specific patterns of functional connectivity involved in consciousness.

\section{Neuroimaging studies}

Neuroimaging studies should further exploit within-state, notask paradigms to differentiate between the full NCC and neural correlates of responsiveness (Koch et al., 2016a). With respect to conscious content, pooling across an exhaustive set of different experiments (as in Axelrod et al., 2015), including a formal comparison between them (Rutiku et al., 2016) and a combination of report and no-report paradigms (Tsuchiya et al., 2016), should help to identify content-specific NCC as the brain regions most consistently activated in the presence of specific conscious percepts. Systematic meta-analyses using reverse inference will be useful to assess the reliability of NCC candidates while avoiding cherry-picking (Moran and Zaki, 2013). Meta-analytic frameworks, such as Neurosynth, should be modified by explicitly incorporating the dissociation between consciousness and cognitive functions, such as attention, working memory, and task ex- 
ecution. Prospective studies should confirm that the full NCC identified through forward and reverse inferences remains the best predictor for the presence of consciousness across different physiological or pathological states, at the level of single trials, or even online, in real time (as in Siclari et al., 2017). Decoding studies should also explicitly compare the predictive value of different neural activity patterns for specific conscious contents (as in Emrich et al., 2013). Finally, prospective studies should be used to assess the clinical utility of different NCC candidates for detecting consciousness in brain-damaged patients (as in Demertzi et al., 2015; Stender et al., 2016).

Response from Dual Perspectives Companion Authors-Brian Odegaard, Robert T. Knight, and Hakwan Lau

We welcome the opportunity to address the issues raised by Boly et al. Much of the basis of our disagreement with their views has already been covered in our article. In essence, we think it is misguided to downplay the role of the PFC in conscious perception based on their selective review of the literature.

One useful point Boly et al. raised is that we should carefully distinguish between different aspects of consciousness. In the case of patients with large bilateral prefrontal lesions, we argued that they lack consciousness in the sense of not displaying goal-directed, meaningful interaction with objects in the external world. But one may ask: do they specifically have normal subjective perceptual experiences? Arguably, the most challenging and conceptually important questions about consciousness concern subjective experiences.

To clarify the issue, we included a video of such a patient. Our point is that this question is difficult to address in a decisive manner, given the inability of these lateral frontal lesioned patients to provide meaningful responses to queries. Notice also the striking difference compared with another patient with extensive damage to the orbitofrontal cortex, highlighting the regional differences in prefrontal damage and conscious behavior.

Despite this difficulty, other evidence based on transcranial magnetic stimulation (Rounis et al., 2010) and frontal lesions (Fleming et al., 2014) shows that such patients are impaired in subjective perceptual experience.

We also want to reemphasize that patients with extensive bilateral parieto-occipital damage with visual agnosias are also conscious by the criteria of showing goal-directed actions toward the external world. This is not to say that these regions are not critical for aspects of sensory perception, as noted by Boly et al.

We think that this exchange is an important reminder that data interpretation often depends on details. As such, we are unsure about their suggestion that we can make use of meta-analytic databases, such as Neurosynth, to definitively settle these issues. In some areas of research, meta-analysis is no doubt useful. But consciousness is an emerging field, where discussion regarding, for example, what counts as an appropriate experimental design, what existing measures are valid, and how to control for confounds, is important.

A case in point is perhaps a recent study by some of the same authors as Boly et al. on EEG correlates of dreams (Siclari et al., 2017). As pointed out in our article, a significant finding emerged in PFC but was not emphasized, similar to other examples in recent literature. A meta-analytic study may well miss the positive prefrontal results because they were not reported and highlighted as main findings by the authors. Such meta-analytic approaches may also overemphasize neuroimaging methods with limited sensitivity.

Instead, we advocate the importance of continuing the present kind of conversation in depth. Traditionally, much discussion on human consciousness takes the form of authoritative scholars advocating intriguing theories and ideas, but placing relatively little emphasis on conflicting data. To make true progress as a rigorous scientific field, we need open and legitimate platforms, on which theoretical viewpoints are critically scrutinized and evaluated from multiple angles. The meetings for the Association for the Scientific Studies of Consciousness provide excellent opportunities for us to continue these kind of debates, as well as the opportunity to keep up to date with this burgeoning and exciting literature.

Finally, Boly et al. cite 2 articles in their response (Schoenemann et al, 2005; Kennedy et al, 1998). Boly et al.'s conclusion is that the non area 4 and 6 PFC is only $13 \%$ of the cortical mantle. They fail to notice that the criteria for PFC was tissue anterior to the genu of the corpus callosum. Simple inspection of Fig 1a in Schoenemann et al (2005) reveals that this method severely underestimates PFC (note the location of the central sulcus on the right of Fig 1a.) The true percentage of non area 4 and 6 PFC is closer to $20-25 \%$ of the cortical mantle.

\footnotetext{
References

Fleming SM, Ryu J, Golfinos JG, Blackmon KE (2014) Domainspecific impairment in metacognitive accuracy following anterior prefrontal lesions. Brain 137:2811-2822. CrossRef Medline

Rounis E, Maniscalco B, Rothwell JC, Passingham RE, Lau H (2010) Theta-burst transcranial magnetic stimulation to the prefrontal cortex impairs metacognitive visual awareness. Cogn Neurosci 1:165-175. CrossRef Medline

Siclari F, Baird B, Perogamvros L, Bernardi G, LaRocque JJ, Riedner B, Boly M, Postle BR, Tononi G (2017) The neural correlates of dreaming. Nat Neurosci 20:872-878. CrossRef Medline
}

\section{References}

Andersen LM, Pedersen MN, Sandberg K, Overgaard M (2016) Occipital MEG activity in the early time range $(<300 \mathrm{~ms})$ predicts graded changes in perceptual consciousness. Cereb Cortex 26:2677-2688. CrossRef Medline

Aru J, Bachmann T, Singer W, Melloni L (2012) Distilling the neural correlates of consciousness. Neurosci Biobehav Rev 36:737-746. CrossRef Medline

Avidan MS, Jacobsohn E, Glick D, Burnside BA, Zhang L, Villafranca A, Karl L, Kamal S, Torres B, O’Connor M, Evers AS, Gradwohl S, Lin N, Palanca BJ, Mashour GA (2011) Prevention of intraoperative awareness in a high-risk surgical population. N Engl J Med 365:591-600. CrossRef Medline 
Axelrod V, Bar M, Rees G (2015) Exploring the unconscious using faces. Trends Cogn Sci 19:35-45. CrossRef Medline

Barton JJ (2011) Disorders of higher visual processing. Handb Clin Neurol 102:223-261. CrossRef Medline

Barton JJ, Cherkasova M (2003) Face imagery and its relation to perception and covert recognition in prosopagnosia. Neurology 61:220-225. CrossRef Medline

Beauchamp MS, Sun P, Baum SH, Tolias AS, Yoshor D (2012) Electrocorticography links human temporoparietal junction to visual perception. Nat Neurosci 15:957-959. CrossRef Medline

Bianchi MT, Sims JR (2008) Restricted diffusion in the splenium of the corpus callosum after cardiac arrest. Open Neuroimag J 2:1-4. CrossRef Medline

Blanke O, Landis T, Seeck M (2000) Electrical cortical stimulation of the human prefrontal cortex evokes complex visual hallucinations. Epilepsy Behav 1:356-361. CrossRef Medline

Blanke O, Ortigue S, Landis T, Seeck M (2002) Stimulating illusory ownbody perceptions. Nature 419:269-270. CrossRef Medline

Blumenfeld H (2011) Neuroanatomy through clinical cases, Ed 2. Sunderland, MA: Sinauer.

Boly M, Seth AK (2012) Modes and models in disorders of consciousness science. Arch Ital Biol 150:172-184. CrossRef Medline

Boly M, Seth AK, Wilke M, Ingmundson P, Baars B, Laureys S, Edelman DB, Tsuchiya N (2013) Consciousness in humans and non-human animals: recent advances and future directions. Front Psychol 4:625. CrossRef Medline

Bor D, Seth AK (2012) Consciousness and the prefrontal parietal network: insights from attention, working memory, and chunking. Front Psychol 3:63. CrossRef Medline

Borchers S, Himmelbach M, Logothetis N, Karnath HO (2011) Direct electrical stimulation of human cortex, the gold standard for mapping brain functions? Nat Rev Neurosci 13:63-70. CrossRef Medline

Brickner RM (1936) The intellectual functions of the frontal lobes. New York: MacMillan.

Brickner RM (1952) Brain of Patient A after bilateral frontal lobectomy: status of frontal-lobe problem. AMA Arch Neurol Psychiatry 68:293-313. CrossRef Medline

Brown EN, Lydic R, Schiff ND (2010) General anesthesia, sleep, and coma. N Engl J Med 363:2638-2650. CrossRef Medline

Cairns H, Oldfield RC, Pennybacker JB, Whitteridge D (1941) Akinetic mutism with an epidermoid cyst of the 3rd ventricle. Brain 64:273-290. CrossRef

Casarotto S, Comanducci A, Rosanova M, Sarasso S, Fecchio M, Napolitani M, Pigorini A, Casali A, Trimarchi PD, Boly M, Gosseries O, Bodart O, Curto F, Landi C, Mariotti M, Devalle G, Laureys S, Tononi G, Massimini M (2016) Stratification of unresponsive patients by a validated index of brain complexity. Ann Neurol 80:718-729. CrossRef Medline

Cavanna AE, Trimble MR (2006) The precuneus: a review of its functional anatomy and behavioural correlates. Brain 129:564-583. CrossRef Medline

Charest I, Kievit RA, Schmitz TW, Deca D, Kriegeskorte N (2014) Unique semantic space in the brain of each beholder predicts perceived similarity. Proc Natl Acad Sci U S A 111:14565-14570. CrossRef Medline

Corbetta M, Shulman GL (2011) Spatial neglect and attention networks. Annu Rev Neurosci 34:569-599. CrossRef Medline

Corkin S (2002) What's new with the amnesic patient H.M.? Nat Rev Neurosci 3:153-160. CrossRef Medline

Craig AD (2010) The sentient self. Brain Struct Funct 214:563-577. CrossRef Medline

Crick F, Koch C (1990) Towards a neurobiological theory of consciousness. Semin Neurosci 2:263-275.

Damasio A, Van Hoesen G (1983) Focal lesions of the limbic lobe. In: Neuropsychology of human emotion (Hellman K, Satz P, eds). New York: Guilford.

Damasio A, Damasio H, Tranel D (2013) Persistence of feelings and sentience after bilateral damage of the insula. Cereb Cortex 23:833-846. CrossRef Medline

de Graaf TA, Sack AT (2014) Using brain stimulation to disentangle neural correlates of conscious vision. Front Psychol 5:1019. CrossRef Medline

de Graaf TA, Hsieh PJ, Sack AT (2012) The 'correlates' in neural correlates of consciousness. Neurosci Biobehav Rev 36:191-197. CrossRef Medline
Dehaene S, Changeux JP (2011) Experimental and theoretical approaches to conscious processing. Neuron 70:200-227. CrossRef Medline

Dehaene S, Naccache L, Cohen L, Bihan DL, Mangin JF, Poline JB, Rivière D (2001) Cerebral mechanisms of word masking and unconscious repetition priming. Nat Neurosci 4:752-758. CrossRef Medline

Del Cul A, Dehaene S, Reyes P, Bravo E, Slachevsky A (2009) Causal role of prefrontal cortex in the threshold for access to consciousness. Brain 132: 2531-2540. CrossRef Medline

Demertzi A, Antonopoulos G, Heine L, Voss HU, Crone JS, de Los Angeles C, Bahri MA, Di Perri C, Vanhaudenhuyse A, Charland-Verville V, Kronbichler M, Trinka E, Phillips C, Gomez F, Tshibanda L, Soddu A, Schiff ND, Whitfield-Gabrieli S, Laureys S (2015) Intrinsic functional connectivity differentiates minimally conscious from unresponsive patients. Brain 138:2619-2631. CrossRef Medline

Desmurget M, Reilly KT, Richard N, Szathmari A, Mottolese C, Sirigu A (2009) Movement intention after parietal cortex stimulation in humans. Science 324:811-813. CrossRef Medline

Desmurget M, Song Z, Mottolese C, Sirigu A (2013) Re-establishing the merits of electrical brain stimulation. Trends Cogn Sci 17:442-449. CrossRef Medline

Eickhoff SB, Bzdok D, Laird AR, Roski C, Caspers S, Zilles K, Fox PT (2011) Co-activation patterns distinguish cortical modules, their connectivity and functional differentiation. Neuroimage 57:938-949. CrossRef Medline

Emrich SM, Riggall AC, Larocque JJ, Postle BR (2013) Distributed patterns of activity in sensory cortex reflect the precision of multiple items maintained in visual short-term memory. J Neurosci 33:6516-6523. CrossRef Medline

Farah M (2004) Visual agnosia. Cambridge, MA: Massachusetts Institute of Technology.

Fischer DB, Boes AD, Demertzi A, Evrard HC, Laureys S, Edlow BL, Liu H, Saper CB, Pascual-Leone A, Fox MD, Geerling JC (2016) A human brain network derived from coma-causing brainstem lesions. Neurology 87: 2427-2434. CrossRef Medline

Foster BL, Parvizi J (2017) Direct cortical stimulation of human posteromedial cortex. Neurology 88:685-691. CrossRef Medline

Frässle S, Sommer J, Jansen A, Naber M, Einhäuser W (2014) Binocular rivalry: frontal activity relates to introspection and action but not to perception. J Neurosci 34:1738-1747. CrossRef Medline

Gaskell AL, Hight DF, Winders J, Tran G, Defresne A, Bonhomme V, Raz A, Sleigh JW, Sanders RD (2017) Frontal alpha- $\delta$ EEG does not preclude volitional response during anaesthesia: EEG findings from a prospective cohort study using the isolated forearm technique. Br J Anaesth, in press.

George MS, Parekh PI, Rosinsky N, Ketter TA, Kimbrell TA, Heilman KM, Herscovitch P, Post RM (1996) Understanding emotional prosody activates right hemisphere regions. Arch Neurol 53:665-670. CrossRef Medline

Gorgolewski KJ, Varoquaux G, Rivera G, Schwartz Y, Sochat VV, Ghosh SS, Maumet C, Nichols TE, Poline JB, Yarkoni T, Margulies DS, Poldrack RA (2016) NeuroVault.org: a repository for sharing unthresholded statistical maps, parcellations, and atlases of the human brain. Neuroimage 124: 1242-1244. CrossRef Medline

Gosseries O, Di H, Laureys S, Boly M (2014) Measuring consciousness in severely damaged brains. Annu Rev Neurosci 37:457-478. CrossRef Medline

Haynes JD (2009) Decoding visual consciousness from human brain signals. Trends Cogn Sci 13:194-202. CrossRef Medline

Hebb DO, Penfield W (1940) Human behavior after extensive bilateral removal from the frontal lobes. Arch Neurol Psychol 44:421-438. CrossRef

Henson R (2006) Forward inference using functional neuroimaging: dissociations versus associations. Trends Cogn Sci 10:64-69. CrossRef Medline

Horikawa T, Tamaki M, Miyawaki Y, Kamitani Y (2013) Neural decoding of visual imagery during sleep. Science 340:639-642. CrossRef Medline

Johanson M, Revonsuo A, Chaplin J, Wedlund JE (2003) Level and contents of consciousness in connection with partial epileptic seizures. Epilepsy Behav 4:279-285. CrossRef Medline

Kajimura N, Uchiyama M, Takayama Y, Uchida S, Uema T, Kato M, Sekimoto M, Watanabe T, Nakajima T, Horikoshi S, Ogawa K, Nishikawa M, Hiroki M, Kudo Y, Matsuda H, Okawa M, Takahashi K (1999) Activity of midbrain reticular formation and neocortex during the progression of human non-rapid eye movement sleep. J Neurosci 19:10065-10073. Medline

Kampfl A, Schmutzhard E, Franz G, Pfausler B, Haring HP, Ulmer H, Felber 
S, Golaszewski S, Aichner F (1998) Prediction of recovery from posttraumatic vegetative state with cerebral magnetic-resonance imaging. Lancet 351:1763-1767. CrossRef Medline

Keller CJ, Honey CJ, Mégevand P, Entz L, Ulbert I, Mehta AD (2014) Mapping human brain networks with cortico-cortical evoked potentials. Philos Trans R Soc Lond B Biol Sci 369:20130528. CrossRef Medline

King JR, Sitt JD, Faugeras F, Rohaut B, El Karoui I, Cohen L, Naccache L, Dehaene S (2013) Information sharing in the brain indexes consciousness in noncommunicative patients. Curr Biol 23:1914-1919. CrossRef Medline

King JR, Pescetelli N, Dehaene S (2016) Brain mechanisms underlying the brief maintenance of seen and unseen sensory information. Neuron 92: 1122-1134. CrossRef Medline

Koch C, Tsuchiya N (2012) Attention and consciousness: related yet different. Trends Cogn Sci 16:103-105. CrossRef Medline

Koch C, Massimini M, Boly M, Tononi G (2016a) Neural correlates of consciousness: progress and problems. Nat Rev Neurosci 17:307-321. CrossRef Medline

Koch C, Massimini M, Boly M, Tononi G (2016b) Posterior and anterior cortex, where is the difference that makes the difference? Nat Rev Neurosci. Advance online publication. doi: 10.1038/nrn.2016.105. CrossRef Medline

Koenigs M, Young L, Adolphs R, Tranel D, Cushman F, Hauser M, Damasio A (2007) Damage to the prefrontal cortex increases utilitarian moral judgements. Nature 446:908-911. CrossRef Medline

Koivisto M, Revonsuo A (2010) Event-related brain potential correlates of visual awareness. Neurosci Biobehav Rev 34:922-934. CrossRef Medline

Kozuch B (2014) Prefrontal lesion evidence against higher-order theories of consciousness. Philos Stud. 167:721-746. CrossRef

Kriegeskorte N (2011) Pattern-information analysis: from stimulus decoding to computational-model testing. Neuroimage 56:411-421. CrossRef Medline

Kundishora AJ, Gummadavelli A, Ma C, Liu M, McCafferty C, Schiff ND, Willie JT, Gross RE, Gerrard J, Blumenfeld H (2017) Restoring conscious arousal during focal limbic seizures with deep brain stimulation. Cereb Cortex 27:1964-1975. CrossRef Medline

Lamme VA (2006) Towards a true neural stance on consciousness. Trends Cogn Sci 10:494-501. CrossRef Medline

Lau H, Rosenthal D (2011) Empirical support for higher-order theories of conscious awareness. Trends Cogn Sci 15:365-373. CrossRef Medline

Laureys S, Schiff ND (2012) Coma and consciousness: paradigms (re)framed by neuroimaging. Neuroimage 61:478-491. CrossRef Medline

Laureys S, Owen AM, Schiff ND (2004) Brain function in coma, vegetative state, and related disorders. Lancet Neurol 3:537-546. CrossRef Medline

Lou HC, Kjaer TW, Friberg L, Wildschiodtz G, Holm S, Nowak M (1999) A ${ }^{15} \mathrm{O}-\mathrm{H}_{2} \mathrm{O}$ PET study of meditation and the resting state of normal consciousness. Hum Brain Mapp 7:98-105. CrossRef Medline

Lumer ED, Friston KJ, Rees G (1998) Neural correlates of perceptual rivalry in the human brain. Science 280:1930-1934. CrossRef Medline

Mah YH, Husain M, Rees G, Nachev P (2014) Human brain lesion-deficit inference remapped. Brain 137:2522-2531. CrossRef Medline

Markowitsch HJ, Kessler J (2000) Massive impairment in executive functions with partial preservation of other cognitive functions: the case of a young patient with severe degeneration of the prefrontal cortex. Exp Brain Res 133:94-102. CrossRef Medline

Mataró M, Jurado MA, García-Sánchez C, Barraquer L, Costa-Jussà FR, Junqué C (2001) Long-term effects of bilateral frontal brain lesion: 60 years after injury with an iron bar. Arch Neurol 58:1139-1142. CrossRef Medline

Meador KJ, Revill KP, Epstein CM, Sathian K, Loring DW, Rorden C (2017) Neuroimaging somatosensory perception and masking. Neuropsychologia 94:44-51. CrossRef Medline

Mégevand P, Groppe DM, Goldfinger MS, Hwang ST, Kingsley PB, Davidesco I, Mehta AD (2014) Seeing scenes: topographic visual hallucinations evoked by direct electrical stimulation of the parahippocampal place area. J Neurosci 34:5399-5405. CrossRef Medline

Melloni L, Schwiedrzik CM, Müller N, Rodriguez E, Singer W (2011) Expectations change the signatures and timing of electrophysiological correlates of perceptual awareness. J Neurosci 31:1386-1396. CrossRef Medline

Mettler FA (1949) Selective partial ablation of the frontal cortex, a correlative study of its effects on human psychotic subjects. New York: Hoebar.

Miller SM (2007) On the correlation/constitution distinction problem (and other hard problems) in the scientific study of consciousness. Acta Neuropsychiatr 19:159-176. CrossRef Medline

Moran JM, Zaki J (2013) Functional neuroimaging and psychology: what have you done for me lately? J Cogn Neurosci 25:834-842. CrossRef Medline

Moruzzi G, Magoun HW (1949) Brain stem reticular formation and activation of the EEG. Electroencephalogr Clin Neurophysiol 1:455-473. CrossRef Medline

Nishimoto S, Vu AT, Naselaris T, Benjamini Y, Yu B, Gallant JL (2011) Reconstructing visual experiences from brain activity evoked by natural movies. Curr Biol 21:1641-1646. CrossRef Medline

Noy N, Bickel S, Zion-Golumbic E, Harel M, Golan T, Davidesco I, Schevon CA, McKhann GM, Goodman RR, Schroeder CE, Mehta AD, Malach R (2015) Ignition's glow: ultra-fast spread of global cortical activity accompanying local "ignitions" in visual cortex during conscious visual perception. Conscious Cogn 35:206-224. CrossRef Medline

Parvizi J, Rangarajan V, Shirer WR, Desai N, Greicius MD (2013) The will to persevere induced by electrical stimulation of the human cingulate gyrus. Neuron 80:1359-1367. CrossRef Medline

Pascual-Leone A, Gates JR, Dhuna A (1991) Induction of speech arrest and counting errors with rapid-rate transcranial magnetic stimulation. Neurology 41:697-702. CrossRef Medline

Penfield W (1959) The interpretive cortex; the stream of consciousness in the human brain can be electrically reactivated. Science 129:1719-1725. CrossRef Medline

Penfield W, Jasper HH (1954) Epilepsy and the functional anatomy of the brain. Boston: Little Brown.

Perogamvros L, Baird B, Seibold M, Riedner B, Boly M, Tononi G (2017) The phenomenal contents and neural correlates of spontaneous thoughts across wakefulness, NREM sleep and REM sleep. J Cogn Neurosci. Advance online publication. doi: 10.1162/jocn_a_01155. CrossRef Medline

Pigorini A, Sarasso S, Proserpio P, Szymanski C, Arnulfo G, Casarotto S, Fecchio M, Rosanova M, Mariotti M, Lo Russo G, Palva JM, Nobili L, Massimini M (2015) Bistability breaks-off deterministic responses to intracortical stimulation during non-REM sleep. Neuroimage 112:105113. CrossRef Medline

Pitts MA, Martínez A, Hillyard SA (2012) Visual processing of contour patterns under conditions of inattentional blindness. J Cogn Neurosci 24: 287-303. CrossRef Medline

Pitts MA, Metzler S, Hillyard SA (2014) Isolating neural correlates of conscious perception from neural correlates of reporting one's perception. Front Psychol 5:1078. CrossRef Medline

Poldrack RA (2006) Can cognitive processes be inferred from neuroimaging data? Trends Cogn Sci 10:59-63. CrossRef Medline

Poldrack RA, Farah MJ (2015) Progress and challenges in probing the human brain. Nature 526:371-379. CrossRef Medline

Poldrack RA, Yarkoni T (2016) From brain maps to cognitive ontologies: informatics and the search for mental structure. Annu Rev Psychol 67: 587-612. CrossRef Medline

Popa I, Donos C, Barborica A, Opris I, Mălîia MD, Ene M, Ciurea J, Mîndruță I (2016) Intrusive thoughts elicited by direct electrical stimulation during stereo-electroencephalography. Front Neurol 7:114. CrossRef Medline

Postle BR (2015) The cognitive neuroscience of visual short-term memory. Curr Opin Behav Sci 1:40-46. CrossRef Medline

Quiroga RQ (2012) Concept cells: the building blocks of declarative memory functions. Nat Rev Neurosci 13:587-597. CrossRef Medline

Rangarajan V, Hermes D, Foster BL, Weiner KS, Jacques C, Grill-Spector K, Parvizi J (2014) Electrical stimulation of the left and right human fusiform gyrus causes different effects in conscious face perception. J Neurosci 34:12828-12836. CrossRef Medline

Rauschecker AM, Dastjerdi M, Weiner KS, Witthoft N, Chen J, Selimbeyoglu A, Parvizi J (2011) Illusions of visual motion elicited by electrical stimulation of human MT complex. PLoS One 6:e21798. CrossRef Medline

Rutiku R, Aru J, Bachmann T (2016) General markers of conscious visual perception and their timing. Front Hum Neurosci 10:23. CrossRef Medline

Samaha J, Gosseries O, Postle BR (2017) Distinct oscillatory frequencies underlie excitability of human occipital and parietal cortex. J Neurosci 37:2824-2833. CrossRef Medline 
Sandberg K, Andersen LM, Overgaard M (2014) Using multivariate decoding to go beyond contrastive analyses in consciousness research. Front Psychol 5:1250. CrossRef Medline

Sanders RD, Tononi G, Laureys S, Sleigh JW (2012) Unresponsiveness not equal unconsciousness. Anesthesiology 116:946-959. CrossRef Medline

Schiff ND (2010) Recovery of consciousness after brain injury: a mesocircuit hypothesis. Trends Neurosci 33:1-9. CrossRef Medline

Schiff ND, Giacino JT, Kalmar K, Victor JD, Baker K, Gerber M, Fritz B, Eisenberg B, Biondi T, O'Connor J, Kobylarz EJ, Farris S, Machado A, McCagg C, Plum F, Fins JJ, Rezai AR (2007) Behavioural improvements with thalamic stimulation after severe traumatic brain injury. Nature 448: 600-603. CrossRef Medline

Selimbeyoglu A, Parvizi J (2010) Electrical stimulation of the human brain: perceptual and behavioral phenomena reported in the old and new literature. Front Hum Neurosci 4:46. CrossRef Medline

Seth AK, Suzuki K, Critchley HD (2011) An interoceptive predictive coding model of conscious presence. Front Psychol 2:395. CrossRef Medline

SiclariF, LaRocqueJJ, Bernardi G, Postle BR, TononiG (2014) The neural correlates of consciousness in sleep: a no-task, within-state paradigm. BioRXiv. Available at: http://www.biorxiv.org/content/early/2014/12/30/012443.

Siclari F, Baird B, Perogamvros L, Bernardi G,LaRocque JJ, Riedner B, Boly M, Postle BR, Tononi G (2017) The neural correlates of dreaming. Nat Neurosci 20:872-878. CrossRef Medline

Silvanto J, Pascual-Leone A (2012) Why the assessment of causality in brain-behavior relations requires brain stimulation. J Cogn Neurosci 24: 775-777. CrossRef Medline

Sirigu A, Daprati E, Ciancia S, Giraux P, Nighoghossian N, Posada A, Haggard $P$ (2004) Altered awareness of voluntary action after damage to the parietal cortex. Nat Neurosci 7:80-84. CrossRef Medline

Solms M (2014) The neuropsychology of dreams: a clinico-anatomical study. New York: Psychology.

Stender J, Mortensen KN, Thibaut A, Darkner S, Laureys S, Gjedde A, Kupers $R$ (2016) The minimal energetic requirement of sustained awareness after brain injury. Curr Biol 26:1494-1499. CrossRef Medline

Tononi G, Boly M, Massimini M, Koch C (2016a) Integrated information theory: from consciousness to its physical substrate. Nat Rev Neurosci 17:450-461. CrossRef Medline

Tononi G, Boly M, Gosseries O, Laureys S (2016b) The neurology of consciousness: an overview. In: The neurology of consciousness, Ed 2 (Laureys S, Tononi G, eds), pp 463-471. Amsterdam: Elsevier.

Tsuchiya N, Koch C (2016) The relationship between consciousness and top-down attention. In: The neurology of consciousness, Ed 2 (Tononi G, Gosseries O, Laureys S, eds), pp 69-89. Amsterdam: Elsevier.

Tsuchiya N, Wilke M, Frässle S, Lamme VA (2015) No-report paradigms: extracting the true neural correlates of consciousness. Trends Cogn Sci 19:757-770. CrossRef Medline

Tsuchiya N, Frässle S, Wilke M, Lamme V (2016) No-report and reportbased paradigms jointly unravel the NCC: response to Overgaard and Fazekas. Trends Cogn Sci 20:242-243. CrossRef Medline

Vanhaudenhuyse A, Noirhomme Q, Tshibanda LJ, Bruno MA, Boveroux P, Schnakers C, Soddu A, Perlbarg V, Ledoux D, Brichant JF, Moonen G, Maquet P, Greicius MD, Laureys S, Boly M (2010) Default network connectivity reflects the level of consciousness in non-communicative braindamaged patients. Brain 133:161-171. CrossRef Medline

von Arx SW, Müri RM, Heinemann D, Hess CW, Nyffeler T (2010) Anosognosia for cerebral achromatopsia: a longitudinal case study. Neuropsychologia 48:970-977. CrossRef Medline

Winawer J, Parvizi J (2016) Linking electrical stimulation of human primary visual cortex, size of affected cortical area, neuronal responses, and subjective experience. Neuron 92:1213-1219. CrossRef Medline

Wu X, Zou Q, Hu J, Tang W, Mao Y, Gao L, Zhu J, Jin Y, Wu X, Lu L, Zhang Y, Zhang Y, Dai Z, Gao JH, Weng X, Zhou L, Northoff G, Giacino JT, He Y, Yang Y (2015) Intrinsic functional connectivity patterns predict consciousness level and recovery outcome in acquired brain injury. J Neurosci 35:12932-12946. CrossRef Medline

Yarkoni T, Poldrack RA, Van Essen DC, Wager TD (2010) Cognitive neuroscience 2.0: building a cumulative science of human brain function. Trends Cogn Sci 14:489-496. CrossRef Medline

Yarkoni T, Poldrack RA, Nichols TE, Van Essen DC, Wager TD (2011) Large-scale automated synthesis of human functional neuroimaging data. Nat Methods 8:665-670. CrossRef Medline 